\title{
Colorectal Adenomatous Polyp
}

National Cancer Institute

\section{Source}

National Cancer Institute. Colorectal Adenomatous Polyp. NCI Thesaurus. Code C96478.

A polypoid adenoma that arises from and protrudes into the lumen of the colon or rectum. Epithelial dysplasia is always present. According to the architectural pattern it is classified as tubular, tubulovillous, or villous. 